\title{
A NATURAL ANTIOXIDANTS OF FOOD PLANT - CHRYSANTHEMUM NANKINGENSE, BASED ON ITS ANTIOXIDANT ACTIVITY WITH ACID POLYSACCHARIDES
}

\author{
MA, Y.-P. ${ }^{*}-$ HU, J. ${ }^{1}-$ LUO, J.-M. ${ }^{1}-$ ZHAO, L. ${ }^{2}$ \\ ${ }^{1}$ College of Life and Health Sciences, Northeastern University \\ Shenyang, Liaoning 110004, China \\ ${ }^{2}$ College of Life Sciences, Northwest A\&F University, Yangling, Shaanxi 712100, China \\ ${ }^{*}$ Corresponding author \\ e-mail: mypluna@sina.com
}

(Received 25th Jun 2019; accepted 24 $4^{\text {th }}$ Oct 2019)

\begin{abstract}
Plant polysaccharides exhibit good antioxidant activity and might represent potential novel antioxidants. Chemical composition, characteristics, and biological activity of plant polysaccharides vary between different species. Chrysanthemum nankingense, a vegetable in South China, contains many active chemicals which have been used as materials in medicine to treat various conditions. Here, we extracted crude polysaccharides from Chrysanthemum nankingense plant using ultrasonic-assisted extraction with a $1: 35(\mathrm{w} / \mathrm{v})$ ratio of leaf powder to water, extraction time of $1 \mathrm{~h}$ at $60^{\circ} \mathrm{C}$. CNP-1 was isolated, using anion-exchange chromatography on a diethylaminoethyl-cellulose column. We determined molecular weight and chemical composition of the fractions using Fourier transform infrared spectroscopy (FT-IR), high-performance liquid chromatography (HPLC), and nuclear magnetic resonance (NMR) spectrometry. Monosaccharide composition analysis indicated that glucuronic acid was the most abundant unit in CNP-1 polysaccharide fractions. Superoxide radical scavenging assessment, 2, 2-diphenyl-1- picrylhydrazyl (DPPH) assay, and a ferric reducing ability of plasma (FRAP) indicated that CNP-1 has significant antioxidant activity in a dose-dependent manner. In summary, $C$. nankingense contains acidic polysaccharides that may represent a promising natural source of antioxidants for healthy food.
\end{abstract}

Keywords: Chrysanthemum nankingense, polysaccharide, structure characterize, antioxidant activities, in vitro

\section{Introduction}

Polysaccharides derived from natural sources are associated with a wide range of therapeutic effects and health-improvement properties (Wang et al., 2016). Polysaccharides are effective antioxidants, and may have antitumor, anticancer and antiviral capabilities, and regulate the immune system (Yang et al., 2014). The natural polysaccharides attracted more and more attention for their potential benefits and perceived safety. Polysaccharides extracted from plants have antioxidant effects on free 
radicals, which suggests that they may be helpful, for example, in limiting the effects of aging, lowering blood sugar or adjusting lipid metabolism (Qi et al., 2006; Capek and Turjan, 2009; Chen et al., 2012; Lv et al., 2014). Consequently, the study of naturally occurring polysaccharides in plants might lead to the discovery of a novel source of antioxidants beneficial to humans.

Chrysanthemum nankingense is a perennial herb that belongs to the tribe Anthemideae of Asteraceae (Figure 1). Its young leaves are used as a vegetable in South China. Moreover, it is used by traditional medicine to treat various conditions, including stomach heat, bitter taste in the mouth, constipation, headache or red eyes (Dai and Wen, 2015; Wu et al., 2015).
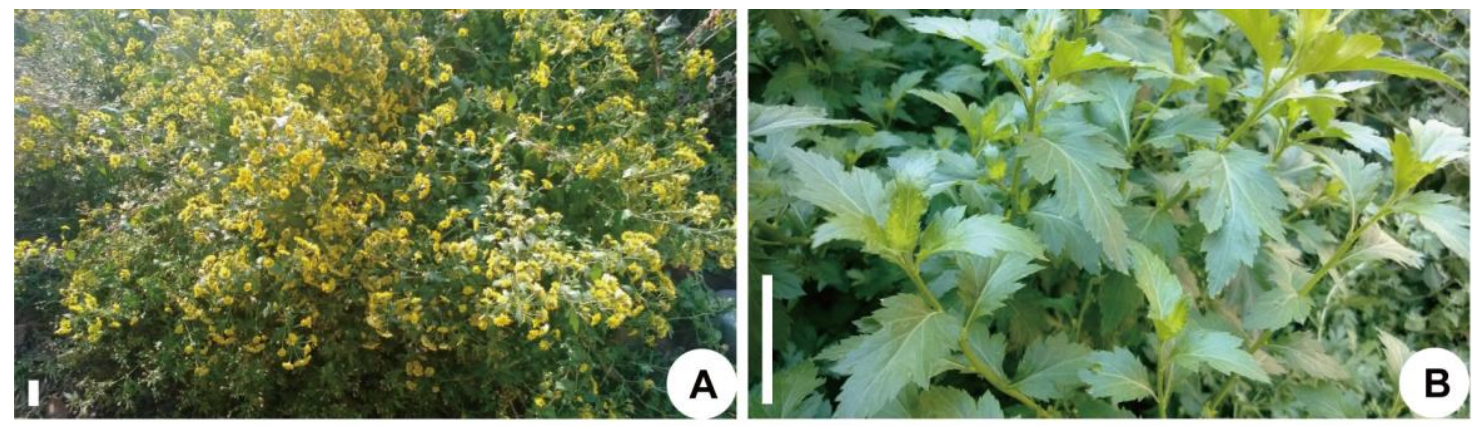

Figure 1. The Chrysanthemum nankingense plant. A) In flower plant (November). B) Foliage plant (September)

C. nankingense contains a variety of organic compounds such as flavonoids, polyphenols, alkaloids, organic acids, borneol, and camphor (Yang et al., 2005; Lv et al., 2007; Wu et al., 2015). However, we have little information on the polysaccharides in $C$. nankingense. In this paper, we isolated the polysaccharides present in $C$. nankingense leaves and characterized their properties by Fourier transform infrared (FT-IR) transmission spectroscopy, high performance liquid chromatography (HPLC), and high performance gel permeation chromatography (HPGPC) and nuclear magnetic resonance (NMR) spectrometry. We further explored the polysaccharides antioxidant activity using a variety of in vitro techniques. The objective of this study was to investigate the natural antioxidants fount in Chrysanthemum nankingense which may be used as a natural source of antioxidants for healthy food.

\section{Materials and methods}

\section{Materials}

Chrysanthemum nankingense plants used in this study were collected in the Hubei province, grown in the Nursery Garden of Northeastern University of China. Fresh leaves were collected and washed with distilled water, defatted with two $95 \%$ ethanol 
washes, and dried in vacuum for $16 \mathrm{~h}$ at $60^{\circ} \mathrm{C}$. Dry leaves were crushed into powder and filtered with an 80 mesh sieve. The powder was stored in an airtight container at dry place until needed.

All the chemical reagents used were of analytical grade except 2, 2-diphenyl-1picrylhydrazyl (DPPH), Ascorbic acid (Vc) , 1, 3, 5-tri (2-pyridyl) -2, 4, 6-triazine (TPTZ) and DEAE cellulose DE-52 (DEAE-52) were purchased from the Sinopharm Chemical Reagent Co. (Beijing, China).

\section{Extraction of polysaccharide}

About $15 \mathrm{~g}$ powder samples were dissolved into deionized water at a 1:35 (w/v) ratio of powder leaves to water, incubated in a water bath at $60^{\circ} \mathrm{C}$ for $30 \mathrm{~min}$, and subjected to ultrasonic extraction twice for $30 \mathrm{~min}$ at a power of $240 \mathrm{~W}$. The mixture was centrifuged at $3000 \mathrm{rpm}$ for $10 \mathrm{~min}$. Then the supernatant was obtained and condensed in a rotating evaporator until a precipitate appeared. The extracts were disposed by activated carbon and Sevag method for decolorizing and removing free proteins. The polysaccharide was precipitate with $80 \%$ absolute ethanol overnight at $4{ }^{\circ} \mathrm{C}$. The mixture was centrifugated at $3000 \mathrm{rpm}$ for $10 \mathrm{~min}$ and lyophilized to obtain raw C. nankingense polysaccharides (CNP), which were then stored at $-20^{\circ} \mathrm{C}$ for further use.

\section{Separation and purification of crude CNP}

The raw polysaccharides were purified successively by DEAE-52 and Sephadex G-100 chromatography according to the method of Qiao et al. (2009). Five hundred milligrams of crude CNP were dissolved in $10 \mathrm{~mL}$ water and applied onto a DEAE-52 column equilibrated with $20 \mathrm{mM}$ phosphate solution $\left(\mathrm{NaH}_{2} \mathrm{PO}_{4} / \mathrm{Na}_{2} \mathrm{HPO}_{4}, \mathrm{pH}\right.$ 6.8). The column was eluted with the $20 \mathrm{mM}$ phosphate solution and sequentially $\mathrm{NaCl}$-phosphate solution gradient $(0.05,0.1$, and $0.5 \mathrm{M})$ with a flow rate of $2 \mathrm{~mL} / \mathrm{min}$. The eluates ( $5 \mathrm{~mL} / \mathrm{tube})$ were collected and monitored by the sulfuric acid anthrone method (Somani et al., 1987). The fraction was collected, concentrated in a rotating evaporator at $50^{\circ} \mathrm{C}$, dialyzed in a $21 \mathrm{~mm}$ dialysis bag in deionized water for $48 \mathrm{~h}$, and then lyophilized and stored at $-20^{\circ} \mathrm{C}$ till needed.

\section{Characterization of CNPs}

\section{FT-IR spectra analysis of CNPs}

The infrared spectrum of purified fractions grounded into $1 \mathrm{~mm} \mathrm{KBr}$ pellets were determined using a FTIR spectrophotometer (Bruker Tensor 27 FT-IR, Bruker Co., Germany) in the frequency range of $4000-400 \mathrm{~cm}^{-1}$ (Peng et al., 2012). 
Nuclear magnetic resonance (NMR) spectrometric analysis of CNPs

About $30 \mathrm{mg}$ CNP1 was dissolved in $500 \mu \mathrm{L} 99.9 \% \mathrm{D}_{2} \mathrm{O}$ and analysized using Bruker Advance III $600 \mathrm{MHz}$ spectrometer (Bruker Co., Germany) to obtain ${ }^{1} \mathrm{H}$ NMR spectra. Chemical shifts were determined in ppm.

\section{Monosaccharide composition analysis of CNPs}

Ten milligram of purified CNP were complete hydrolyzed by applying $3 \mathrm{~mL}$ trifluoroacetic acid $(2 \mathrm{M})$ at $120^{\circ} \mathrm{C}$ for 6 hours, then centrifuged at $12000 \mathrm{rpm}$ for $5 \mathrm{~min}$ after cooling. $0.2 \mathrm{M} \mathrm{NaOH}$ was added to the supernatant to adjust the $\mathrm{pH}$ to 7.0. The hydrolysate eluted was aadded to $10 \mathrm{~mL}$ and stored in sealed container.

The derivatization was determined following the method of Honda et al. (1989) with some modification. Samples $(10 \mathrm{mg} / \mathrm{mL})$ and monosaccharide standards arabinose, glucuronic acid, glucose, rhamnose, mannose, galactose, and xylose were mixed with $0.2 \mathrm{M} \mathrm{NaOH}$ and $0.5 \mathrm{M}$ 1-phenyl-3-methyl-5-pyrazolone (PMP) solution in $1 \mathrm{~mL}$ test tubes. The solutions were thoroughly mixed and incubated at $70^{\circ} \mathrm{C}$ for $40 \mathrm{~min}$. Then $0.2 \mathrm{M} \mathrm{HCl}$ were used to neutralize the $\mathrm{NaOH}$ after the samples cooled. One hundred microliters of trichloromethane were added to the mixture and completed mixed, then centrifuged $5000 \mathrm{rpm}$ for $10 \mathrm{~min}$. The supernatant was extracted for three times with chloroform. The final supernatant was filtered with a $0.45 \mu \mathrm{m}$ membrane and used for high-performance liquid chromatography (HPLC) with a C18 column $(250 \mathrm{~mm} \times$ $4.6 \mathrm{~mm}, 5 \mu \mathrm{m})$. The mobile phase was $19 \%(\mathrm{~V} / \mathrm{V})$ ammonium acetate buffer solution (pH 5.5) and the flow rate was $1.0 \mathrm{~mL} / \mathrm{min}$.

\section{Determining the molecular weight of CNPS}

Molecular weights were measured by high performance gel permeation chromatography (HPGPC) using a Waters HPLC system equipped with two serially linked TSK-GEL G3000 PWXL $(7.8 \mathrm{~mm} \times 300 \mathrm{~mm})$ columns and RI and connected to a UV detector. The mobile phase was $0.71 \% \mathrm{Na}_{2} \mathrm{SO}_{4}$ and the flow rate was $0.6 \mathrm{~mL} / \mathrm{min}$ and the temperature of column was kept at $35^{\circ} \mathrm{C}$. Molecular weights of the samples were obtained by comparison with a calibration curve created using the Dextran T-series standards with known molecular weights (23800, 80900, 147600 and 273000). The linear equation of the standard curve was: $\log M=-0.34974968 \mathrm{tR}+9.75252445$, with a correlation coefficient of 0.9981 .

\section{Determining the antioxidant activity of CNPs in vitro}

Determining CNPs'scavenging activity against oxide anions

The measurement of polysaccharide scavenging activity against superoxide anions were conducted as previously described (Marklund and Marklund, 1974). First, $4.5 \mathrm{~mL}$ $0.05 \mathrm{M}$ tris- $\mathrm{HCl}$ solution $\left(\mathrm{pH} \mathrm{8.0)}\right.$ was incubated in a water bath at $25^{\circ} \mathrm{C}$ for $20 \mathrm{~min}$. Then $50,100,150$, or $200 \mu \mathrm{L}$ of sample $(2 \mathrm{~g} / \mathrm{L})$ were added and stirred at $25^{\circ} \mathrm{C}$ for 
20 min. Finally, the reaction was terminated by adding $100 \mu \mathrm{L} \mathrm{1,} \mathrm{2,} \mathrm{3-phentriol} \mathrm{(3} \mathrm{M).}$ The mixture of tris- $\mathrm{HCl}$ and 1, 2, 3-phentriol was used as negative control $\left(\mathrm{A}_{0}\right)$. The absorbance of the mixture was measured spectrophotometrically at $325 \mathrm{~nm}$ and the scavenging activity against superoxide anions was calculated according to the following equation: scavenging effect $(\%)=\left(\mathrm{A}_{0}-\right.$ Asample $) / \mathrm{A}_{0} \times 100 \%$; rate of oxidation $(\%)=\left(A_{9}-A_{1}\right) / 3 \times 100 \%$, where $A_{1}$ is the absorbance of the first detection and $A_{9}$ is the absorbance of the ninth detection.

\section{Scavenging ability of DPPH radical}

DPPH radical scavenging activity of CNP was measured following the method reported previously (Jia et al., 2014). Two milliliters of sample at various concentrations $(0.3,0.5$, and $0.7 \mathrm{mg} / \mathrm{mL})$ were added to $2 \mathrm{~mL} \mathrm{DPPH}$ ethanol solution $(0.06 \mathrm{mM})$ in a $5 \mathrm{~mL}$ cuvetteand mixed completely. The mixture was kept in the dark for $20 \mathrm{~min}$ and the absorbance of the sample was measured at $517 \mathrm{~nm}$ using a spectrophotometer $(721 \mathrm{G}$, China). Ascorbic acid ( $\mathrm{Vc}$ ) was used as the control. The scavenging rate was obtained according the formula: DPPH radical scavenging activity $(\%)=(1-\mathrm{As} / \mathrm{Ab}) \times 100 \%$, where As is the absorbance of the sample, and $\mathrm{Ab}$ is the absorbance of the blank.

\section{Assessment of iron reducing activity}

The ferric reducing activity of plasma (FRAP) was measured following the method reported by Jia et al. (2014), with some modifications. Fresh FRAP reaction solution was prepared by mixing $25 \mathrm{~mL}$ acetate buffer $(300 \mathrm{mM}$; $\mathrm{pH} 3.6)$ with $2.5 \mathrm{~mL} \mathrm{1,} \mathrm{3,} \mathrm{5-tri}$ (2-pyridyl) -2, 4, 6-triazine (TPTZ) solutions (10 mM) and $2.5 \mathrm{~mL} \mathrm{FeCl}_{3} \cdot 6 \mathrm{H}_{2} \mathrm{O}$ (20 mM). Then, $1000 \mu \mathrm{L}$ of the sample were put into a cuvette to measure the initial absorbance after the sample was warmed to $37^{\circ} \mathrm{C}$. The absorption of the solution was measured at $593 \mathrm{~nm}$ while $40 \mu \mathrm{L}$ sample at different concentration $(0.2,0.4,0.8$ or $1.0 \mathrm{mg} / \mathrm{mL}$ ) were added to the cuvette. The absorption value was recorded at $10 \mathrm{~s}$ intervals until it reached a plateau. Iron reducing activity was calculated referencing to the calibration curve prepared of $\mathrm{FeSO}_{4} \cdot 7 \mathrm{H}_{2} \mathrm{O}$ solution with several concentrations (100-1000 M). Three technical replicates were conducted for each analysis mentioned above. Three parallel measurements and technical replicates were conducted for each analysis mentioned above. All the data were processed in Origin 8.5.1.

\section{Results and discussion}

\section{Purification and segregation of CNP}

We obtained the primary polysaccharides from $C$. nankingense using ultrasonic pretreatment with an isolation time of 5 hours, raw materials to water ratio of 1:35 (w/v), power of $240 \mathrm{~W}$, and a combination of activated carbon decolorization and Sevag method to remove the pigment and proteins. The yield of raw polysaccharide from 
C. nankingense was about 4.32\%. Four elution peaks (CNP-1, CNP-2, CNP-3, and CNP-4) were presented from the crude CNP using a DEAE-52 cellulose anion-exchange chromatogram (Figure 2). The major fraction CNP-1 was condensed and lyophilized for next analysis.

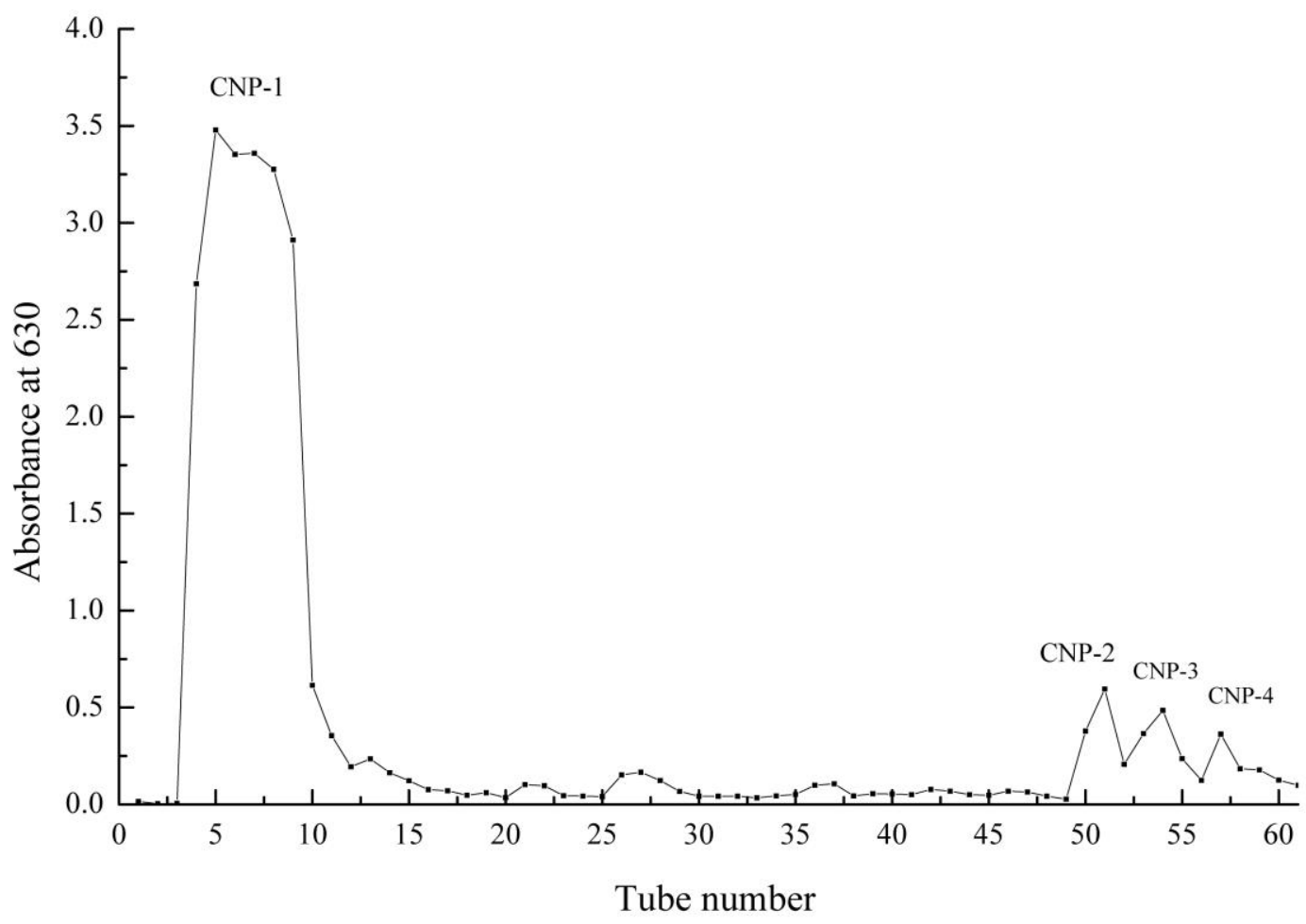

Figure 2. Elution curve of crude Chrysanthemum nankingense polysaccharide detected by sulfuric acid anthrone method at $490 \mathrm{~nm}$ using DEAE52-cellulose column chromatography. CNP-1 was eluted by phosphate solution. CNP-2, CNP-3, and CNP-4 were eluted by $0.5 \mathrm{M}$ $\mathrm{NaCl}$-phosphate solution

\section{Structure analysis of CNP-1}

FT-IR spectra analysis of CNP-1

We characterized the absorption of CNP-1 using FT-IR spectrum (Figure 3). This sample showed a wide, intense signals at 3600-3200 $\mathrm{cm}^{-1}$, representing an $\mathrm{O}-\mathrm{H}$ stretching group, and a weak signal at $3000-2800 \mathrm{~cm}^{-1}$, which we attributed to a $\mathrm{C}-\mathrm{H}$ stretching vibration (Jia et al., 2014). We also observed peaks in the region of $1630-1510 \mathrm{~cm}^{-1}$ and $1420 \mathrm{~cm}^{-1}$, attributed to $\mathrm{C}=\mathrm{O}$ asymmetric stretching vibration (Cerna et al., 2003), suggesting the carboxyl groups presenting here (Zha et al., 2012). The peaks at $1000-1200 \mathrm{~cm}^{-1}$ in the CNP-1 polysaccharide fractions suggests the presence of $\mathrm{C}-\mathrm{O}-\mathrm{C}$ and $\mathrm{C}-\mathrm{O}-\mathrm{H}$ signals, possibly an alduronic acid such as glucuronic acid or mannuronic acid. The CNP-1 fractions presented peaks between 3600 and 3200, 
3000 and 2800, 1250 and $1000 \mathrm{~cm}^{-1}$, the typical signals for polysaccharides (You et al., 2014). A characteristic signal at $891 \pm 7 \mathrm{~cm}^{-1}$ was attribute to glycosidic linkages. CNP-1 has a characteristic signal at $937.3 \mathrm{~cm}^{-1}$ induced by asymmetric stretching vibration of pyran ring (Coimbra et al., 1998). Thus, we propose that CNP-1 might be pyranose.

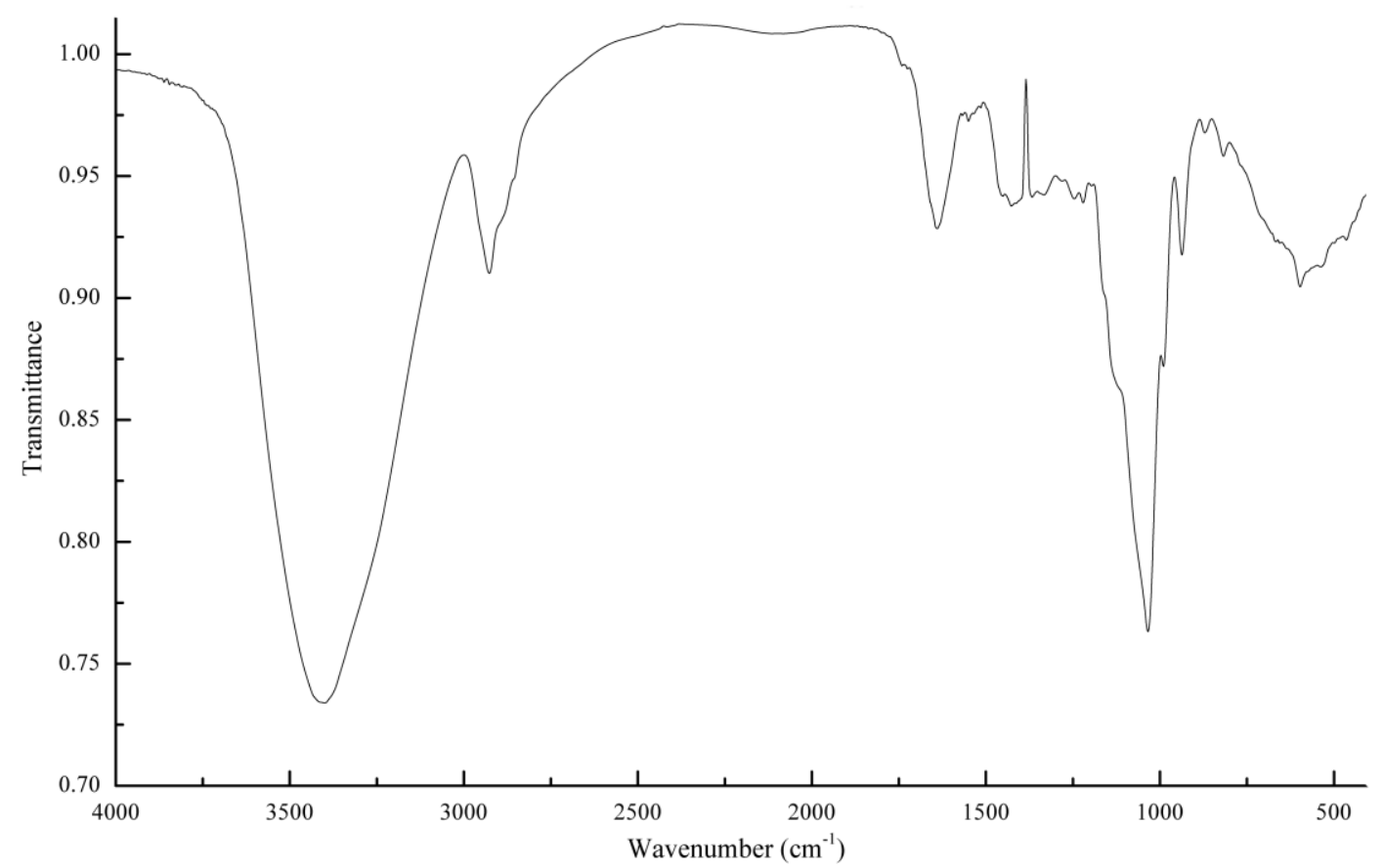

Figure 3. Fourier transform infrared spectra of CNP-1

\section{NMR spectra of CNP-1}

The structural of CNP-1 was confirmed using ${ }^{1} \mathrm{H}-\mathrm{NMR}$ analysis (Figure 4). The spectra of CNP was presented between 3.0-5.3 ppm $\left({ }^{1} \mathrm{H}\right.$ NMR) which were typical signals for polysaccharides (Chen et al., 2016; Wang et al., 2018). The signals induced by protons on sugar rings were present in the region of $3.50-4.50 \mathrm{ppm}$. We predicted that CNP-1 has a-configuration of saccharide residues for all the resonance signals greater than the shift of $4.8 \mathrm{ppm}$ (Chen et al., 2016). This conclusion further confirmed the results of the infrared spectrum.

\section{Monosaccharide analysis of CNP-1}

We characterized the monosaccharide composition of CNP-1 by HPLC (Figure 5). Monosaccharide standards of glucuronic acid, mannose, rhamnose, xylose, glucose, galactose, and arabinose produced well separated peaks, with retention times of 16.18, $21.03,24.47,26.62,30.91,34.12$, and $45.69 \mathrm{~min}$. Glucuronic acid was the most abundant monosaccharide in the CNP-1 fraction; mannose and galactose were also 
present in trace amounts. These results indicate that CNP-1 is primarily composed of sugar acids, which suggests that it may have deoxidizing activity.

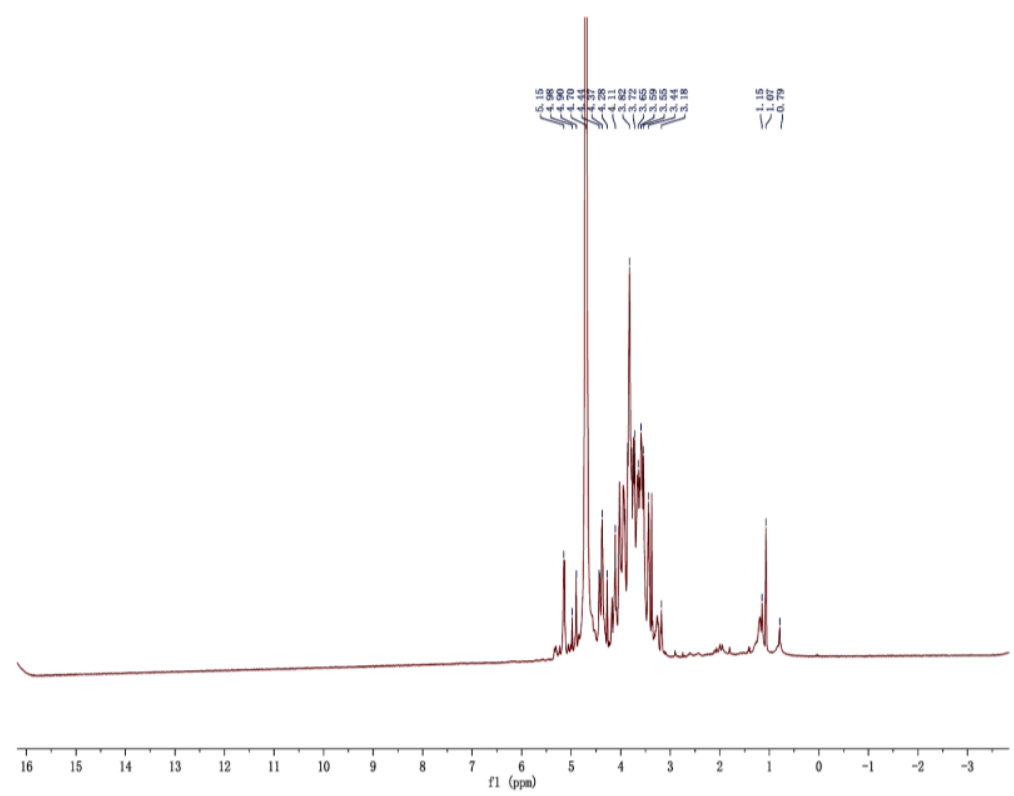

Figure 4. 1H NMR spectra of CNPI
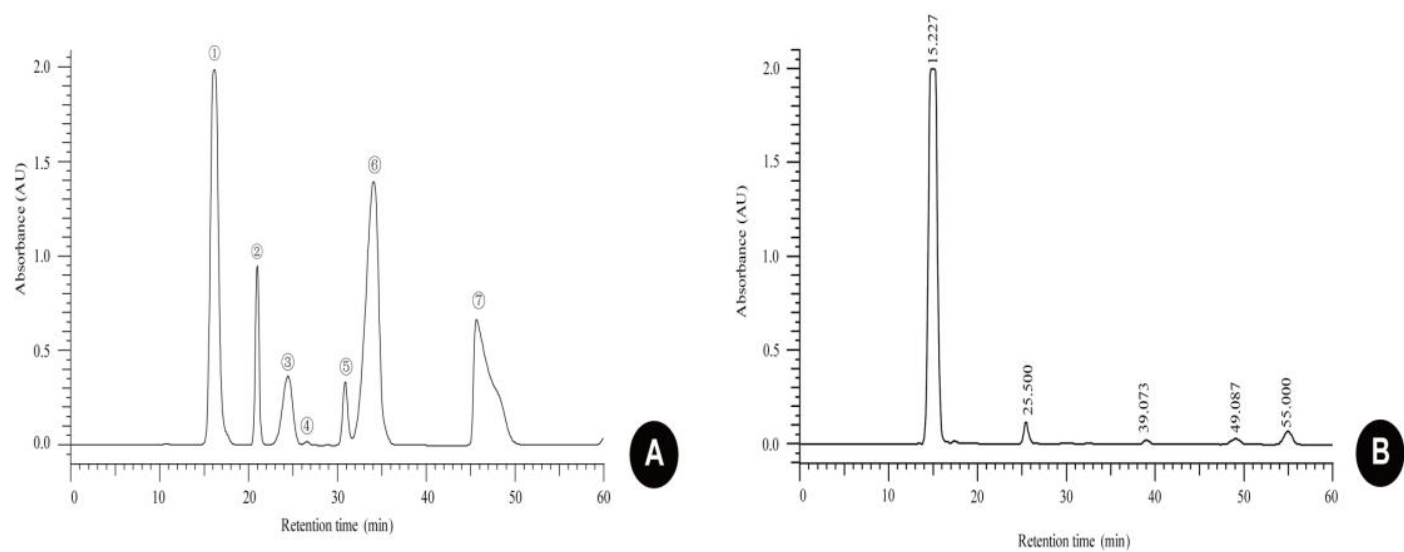

Figure 5. High-performance liquid chromatograms of three monosaccharide fractions isolated from Chrysanthemum nankingense. Part A shows peaks for the monosaccharide standards glucuronic acid (1), L-mannose (2), D-rhamnose (3), L-xylose (4), L-glucose (5), D-galactose (6), and L-arabinose (7). Parts B shows $C$. nankingense monosaccharide fractions $C N P-1$

\section{Molecular weight of CNP-1}

We determined the molecular weight of CNP-1 using the HPGPC method. Based on the reference curve created with dextran standards, we estimated that the average molecular weights of CNP-1 was 4779 Da. 


\section{Antioxidant activity of CNP-1 in vitro}

Using the DPPH assay, we found that the activity to scavenge free radical of CNP-1 at $0.7 \mathrm{mg} \mathrm{mL}^{-1}$ was $21.39 \%$, while that of $\mathrm{Vc}$ was $89.00 \%$ (Figure $6 \mathrm{~A}$ ). The results suggested that CNP-1 had a radicals scavenging effect on DPPH. The FRAP value of CNP-1 increased with the concentration of this fraction (Figure $6 B$ ). At $0.8 \mathrm{mg} / \mathrm{mL}$, the FRAP value of CNP-1 was 2.726 mmol. These results demonstrate that CNP-1 possesses strong ferric reducing activity.
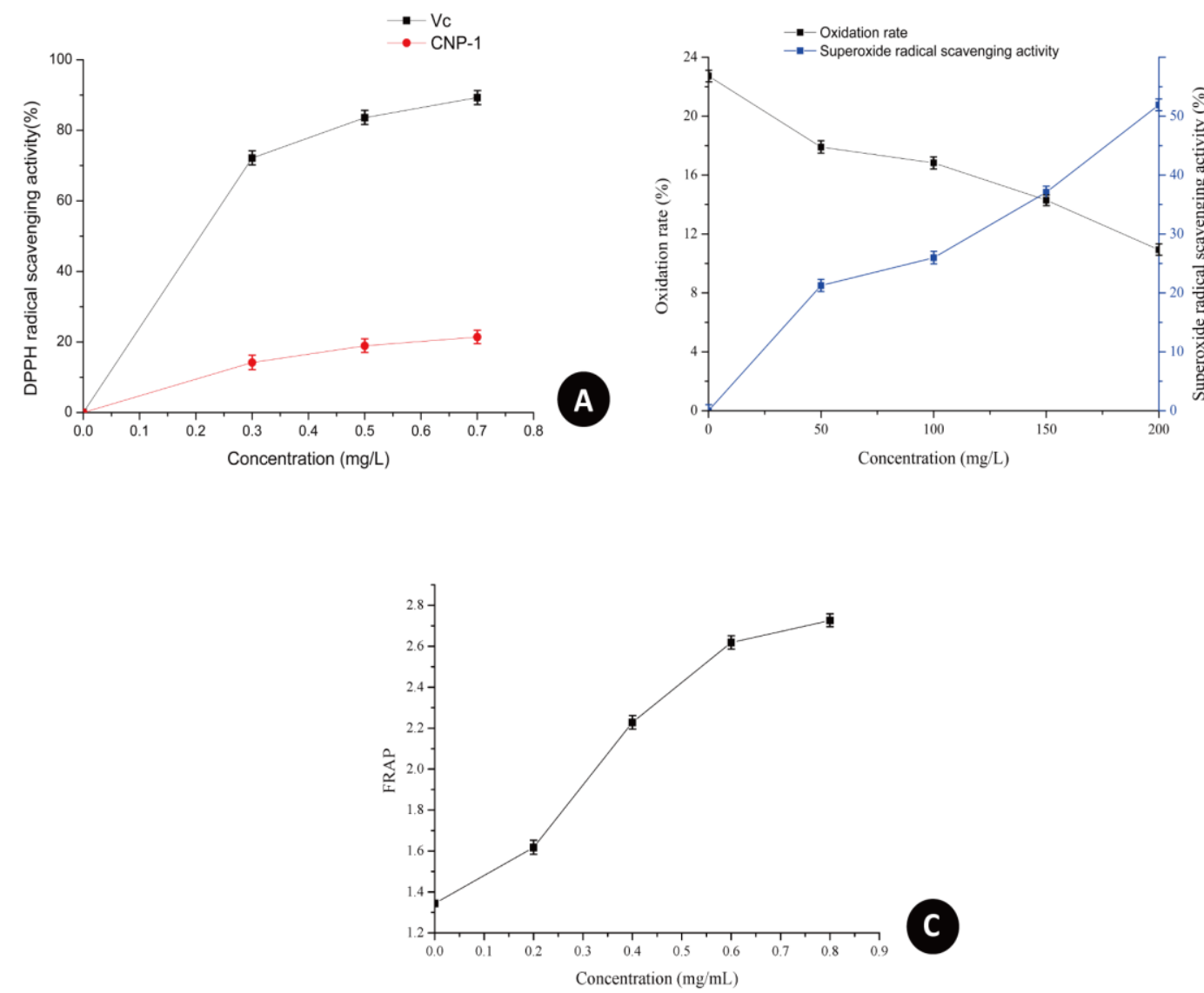

Figure 6. Antioxidant activity of the purified polysaccharide fraction CNP-1. A. DPPH radical scavenging activity. B. Ferric reducing activity. C. Superoxide radical scavenging activity

We measured the scavenging activity of CNP-1 on superoxide radical (Figure 6C), finding that the oxidation rate of the solution decreased with increases in CNP-1 concentration, while with sample concentration increasing, the scavenging activity of CNP-1 increased also. The scavenging activity of CNP-1 reached $51.91 \%$ at the doses of $200 \mathrm{mg} \mathrm{L}^{-1}$. These results demonstrate that CNP-1 is characterized by strong superoxide radical scavenging activity. 


\section{Conclusion}

In this study, we isolated polysaccharides from $C$. nankingense, and characterized its structural features. Glucuronic acid was the main component of the polysaccharides of this plant by monosaccharide composition analysis. Antioxidant activity analysis demonstrated that CNP-1 had high ferric reducing ability and superoxide radical scavenging activity. These findings suggest the polysaccharides from $C$. nankingense leaves might be a potential source of natural antioxidants in functional foods or pharmacological applications. In addition, the studies showed that most of metabolities were associated with the plant phenotypes (Schauer et al., 2006; Sulpice et al., 2009; Chen et al., 2014; Dan et al. 2016). Chrysanthemum is complex taxa with different habitat and various ploidy levels. The phylogeny of Chrysanthemum is still not clear. Polysaccharide, as a widely existed metabolite in plant, might be a new way to explore the relationship between Chrysanthemum species.

Acknowledgements. This work was supported by the National Natural Science Foundation of China (No. 31872710, 31470699 and 31770200). The authors wish to thank X. G. Sang for assistance with the FTIR analysis.

\section{REFERENCES}

[1] Capek, P., Machová, E., Turjan, J. (2009): Scavenging and antioxidant activities of immunomodulating polysaccharides isolated from Salvia officinalis L. - Int J Biol Macromol 44: 75-80.

[2] Cerna, M., Barros, A. S., Nunes, A., Rocha, S. M., Delgadillo, I., Copikova, J., Coimbra, M. A. (2003): Use of FT-IR spectroscopy as a tool for the analysis of polysaccharide food additives. - Carbohyd Ploym 51: 383-389.

[3] Chen, J. J., Zhang, T., Jiang, B., Mu, W. M., Miao, M. (2012): Characterization and antioxidant activity of Ginkgo biloba exocarp polysaccharides. - Carbohyd Ploym 87: 40-45.

[4] Chen, W., Gao, Y., Xie, W., Gong, L., Lu, K., Wang, W. (2014): Genome-wide association analyses provide genetic and biochemical insights into natural variation in rice metabolism. - Science Foundation in China 46: 714-721.

[5] Chen, T., Zhang, M., Li, J., Surhio, M. M., Li, B., Ye, M. (2016): Structural characterization and hypoglycemic activity of trichosanthes, peel polysaccharide. LWT-Food SCI TE 70: 55-62.

[6] Coimbra, M. A., Barros, A., Barros, M., Rutledge, D. N., Delgadillo, I. (1998): Mul-tivariate analysis of uronic acid and neutral sugars in whole pectic samples byFT-IR spectroscopy. - Carbohyd Ploym 37: 241-248.

[7] Dai, S. L., Wen, X. H. (2015): Efficacy of the medicinal and food Chrysanthemum. Chin Bull Life Sci 27: 1083-1089. 
[8] Dan, Z. W., Hu, J., Zhou, W., Yao, G. X., Zhu, R. S., Zhu, Y. G., Huang, W. C. (2016): Metabolic prediction of important agronomic traits in hybrid rice (Oryza sativa L.). Scientific Reports 6: 21732.

[9] Honda, S., Akao, E., Suzuki, S., Okuda, M., Kakehi, K., Nakamura, J. (1989): High-performance liquid chromatography of reducing carbohydrates as strongly ultraviolet-absorbing and electrochemically sensitive 1-phenyl-3-methyl-5-pyrazolone derivatives. - Anal. Biochem 180: 351-357.

[10] Jia, X. J., Ding, C. B., Yuan, S., Zhang, Z. W., Chen, Y. E., Du, L., Yuan, M. (2014): Extraction, purification and characterization of polysaccharides from Hawktea. Carbohyd Ploym 99: 319-32.

[11] Lv, L., Qin, M. J., Wu, G., Han, H. H. (2007): Analysis of essential oil constituents in flower of Dendranthema indicum and D. nankingene from different provenances. - J Plant Resour Env 16: 53-57.

[12] Lv, L. S., Cheng, Y. H., Zheng, T. S., Li, X. M., Zhai, R. (2014): Purification, antioxidant activity and antiglycation of polysaccharides from Polygonum multiflorum Thunb. Carbohyd Ploym 99: 765-773.

[13] Marklund, S., Marklund, G. (1974): Involvement of superoxide anion radicals in the autoxidation of pyrogallol and a convenient assay for superoxide dismutase. - Eur $\mathbf{J}$ Biochem 47: 469-471.

[14] Peng, Z. F., Liu, M., Fang, Z. X., Wu, J. L., Zhang, Q. Q. (2012): Composition and cytotoxicity of a novel polysaccharide from brown alga (Laminaria japonica). Carbohyd Ploym 89: 1022-1026.

[15] Qi, H. M., Zhang, Q. B., Zhao, T. T., Hu, R. G., Zhang, K., Li, Z. E. (2006): In vitroantioxidant activity of acetylated and benzoylated derivatives of polysaccha-ride extracted from Ulva pertusa (Chlorophyta). - Bioorg Med Chem Lett 16: 2441-2445.

[16] Qiao, D., Hu, B., Gan, D., Sun, Y., Ye, H., Zeng, X. (2009): Extraction optimized by usingresponse surface methodology, purification and preliminary characterization ofpolysaccharides from Hyriopsis cumingii. - Carbohydrate Polymers 76: 422-429.

[17] Schauer, N., Semel, Y., Roessner, U., Gur, A., Balbo, I., Carrari, F. (2006): Comprehensive metabolic profiling and phenotyping of interspecific introgression lines for tomato improvement. - Nature Biotechnology 24: 447-454.

[18] Somani, B. L., Khanade, J., Sinha, R. (1987): A modified anthrone-sulfuric acid method for the determination of fructose in the presence of certain proteins. - Anal. Biochem 167: 327-330.

[19] Sulpice, R., Pyl, E. T., Ishihara, H., Trenkamp, S., Steinfath, M., Witucka-Wall, H. (2009): Starch as a major integrator in the regulation of plant growth. - Proc Natl Acad Sci USA 106: 10348-10353.

[20] Wang, P. C., Zhao, S., Yang, B. Y., Wang, Q. H., Kuanga, H. X. (2016): Anti-diabetic polysaccharides from natural sources: a review. - Carbohyd Ploym 148: 86-97. 
[21] Wang, Y., Wei, X., Wang, F., Xu, J., Tang, X., Li, N. (2018): Structural characterization and antioxidant activity of polysaccharide from ginger. - Int J Biol Macromol 111: 862-869.

[22] Wu, S. M., Xu, T., Huang, D. F. (2015): Chemical compositions of the volatile extracts from seeds of Dendranthema nankingense and Borago officinalis. - J Food Drug Anal 23: 253-259.

[23] Yang, N., Ren, A., Hu, W., Qian, S., Duan, J. A., Tian, L. J. (2005): Chemical constituents of Dendranthema nankingense. - J China Pharml University 36: 402-404.

[24] Yang, X. L., Wang, R. F., Zhang, S. P., Zhu, W. J., Tang, J., Liu, J. F., Chen, P., Zhang, D. M., Ye, W. C., Zheng, Y. L. (2014): Polysaccharides from Panax japonicus C. A. Meyer and their antioxidant activities. - Carbohyd Ploym 101: 386-391.

[25] You, Q. H., Yin, X. L., Zhang, S. G., Jiang, Z. H. (2014): Extraction, purification, and antioxidant activities of polysaccharides from Tricholoma mongolicum Imai. - Carbohyd Ploym 99: 1-10.

[26] Zha, X. Q., Xiao, J. J., Zhang, H. N., Wang, J. H., Pan, L. H., Yang, X. F., Luo, J. P. (2012): Polysaccharides in Laminaria japonica (LP): Extraction, physicochemical properties and their hypolipidemic activities in diet-induced mouse model of atherosclerosis. - Food Chem 134: 244-25. 